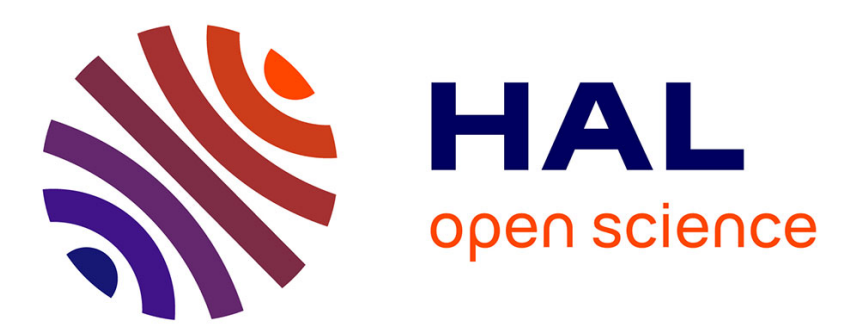

\title{
Energy dependence of defect energy levels in electron irradiated silicon
}

\author{
J. Krynicki, J.C. Bourgoin, G. Vassal
}

\section{To cite this version:}

J. Krynicki, J.C. Bourgoin, G. Vassal. Energy dependence of defect energy levels in electron irradiated silicon. Revue de Physique Appliquée, 1979, 14 (3), pp.481-484. 10.1051/rphysap:01979001403048100 . jpa-00244618

\section{HAL Id: jpa-00244618 https://hal.science/jpa-00244618}

Submitted on 1 Jan 1979

HAL is a multi-disciplinary open access archive for the deposit and dissemination of scientific research documents, whether they are published or not. The documents may come from teaching and research institutions in France or abroad, or from public or private research centers.
L'archive ouverte pluridisciplinaire HAL, est destinée au dépôt et à la diffusion de documents scientifiques de niveau recherche, publiés ou non, émanant des établissements d'enseignement et de recherche français ou étrangers, des laboratoires publics ou privés. 


\title{
Energy dependence of defect energy levels in electron irradiated silicon (*)
}

\author{
J. Krynicki $\left({ }^{* *}\right)$ and J. C. Bourgoin \\ Groupe de Physique des Solides de l'Ecole Normale Supérieure (***) \\ Université Paris VII, Tour 23, 2 place Jussieu, 75221 Paris Cedex 05, France \\ G. Vassal \\ Direction des Recherches, Alsthom-Atlantique, 9, rue Ampère, 91301 Massy, France
}

(Reçu le 18 juillet 1978, révisé le 20 novembre 1978, accepté le 23 novembre 1978)

\begin{abstract}
Résumé. - Nous avons étudié par des techniques capacitives (TSCAP et DLTS) la variation du taux d'introduction des défauts avec l'énergie des électrons dans du silicium de type $\mathrm{n}$ irradié à la température ambiante. Les résultats obtenus confirment de façon directe l'identification des défauts observés qui est proposée dans la littérature : les niveaux à $E_{\mathrm{c}}-0,39 \mathrm{eV}$ et $E_{\mathrm{c}}-0,23 \mathrm{eV}$, attribués à la dilacune, ont une énergie de seuil qui a une valeur double de l'énergie de seuil pour les défauts de type lacunaire (le niveau $E_{\mathrm{c}}-0,43 \mathrm{eV}$ ). Le niveau à $E_{\mathrm{c}}-0,33 \mathrm{eV}$, qui n'a pas encore été identifié, devrait correspondre à un défaut lacunaire puisque son énergie de seuil est de $25 \mathrm{eV}$.
\end{abstract}

\begin{abstract}
We have studied through capacitance techniques (TSCAP and DLTS) the variation of the introduction rate of defects with the energy of the electrons in n-type silicon irradiated at room temperature.

The results obtained provide a direct confirmation of the identification of the observed defects which was proposed in the literature : the $E_{\mathrm{c}}-0.39$ and $E_{\mathrm{c}}-0.23 \mathrm{eV}$ levels, attributed to the divacancy are found to have a threshold whose value is two times the threshold energy $(25 \mathrm{eV})$ for vacancy-type defects (the $E_{\mathrm{c}}-0.43 \mathrm{eV}$ level). The $E_{\mathrm{c}}-0.33 \mathrm{eV}$ which is not yet identified should correspond to a vacancy-type defect since its threshold energy is $25 \mathrm{eV}$.
\end{abstract}

1. Introduction. - Most of the simple point defects produced by electron irradiation in silicon have been identified and their electronic properties determined using conventional techniques (such as electron paramagnetic resonance and optical absorption) [1]. Recently the recombination parameters of some of these defects have been studied using capacitive methods, such as thermally stimulated capacitance (TSCAP) and deep level transient spectroscopy (DLTS) [2, 3]. In silicon only one study [4] deals with defects introduced by electron irradiation at low temperature, i.e. primary defects (vacancies and divacancies), the other studies [5-13] deal with defects introduced by irradiation at room temperature, i.e. defects which are stable at $300 \mathrm{~K}$ (divacancy, $\mathrm{A}$ and $\mathrm{E}$ centers, etc.).

$\left({ }^{*}\right)$ Work supported in part by the Institute of Physics, Polish Academy of Sciences (Warsaw) and by the Délégation à la Recherche Scientifique et Technique under contract $\mathrm{n}^{\circ} \mathbf{7 6 7 0 6 7 6 .}$

${ }^{(* *)}$ Permanent address : Institute Badan Jadrowych, Swierk, Poland.

$\left({ }^{* * *}\right)$ Laboratoire associé au C.N.R.S.
The identification of the defects detected by a capacitive method is made by comparing the energy levels and the annealing temperatures measured with the values found for the defects which have been identified using conventional techniques. Such a way of identifying defects is not without problems because the energy levels and the annealing temperatures determined with conventional techniques are sometimes known with a low accuracy; in addition they can vary with the nature and/or the concentration of the doping impurity, the dose of irradiation, etc. Moreover, a confusion is possible for defects exhibiting similar energy levels.

The aim of this paper is to study, using capacitive techniques, the energy dependence of the defect levels introduced by room temperature electron irradiation in order to distinguish between vacancy and divacancy - type defects and so verify in a direct way the identifications which have been made concerning the divacancy and some of the vacancy associated defects. Vacancy type defects and divacancies correspond to different threshold energies for atomic displacement and consequently to different variations 
of their creation rates (number of defects introduced by one incident electron) versus the energy of irradiation. According to Watkins and Corbett [14] the threshold energies for vacancy and divacancy formation are respectively 25 and $50 \mathrm{eV}$. We shall describe in this paper results obtained using TSCAP and verified through capacitance spectroscopy (DLTS). The samples studied are diodes used as high voltage power rectifiers. The technological aim of the study was to investigate the conditions required to replace gold impurities by electron induced defects in order to produce fast switching rectifiers.

2. Experimental. - The diodes are $p^{+}-n$ structures made by aluminium diffusion in $130 \Omega \mathrm{cm}$ phosphorus doped FZ material. The electrical contacts are made by $\mathrm{n}^{+}$(phosphorus) and $\mathrm{p}^{+}$(gallium) diffusions.

The irradiations are performed with a Van de Graaff machine equipped to produce $150 \mathrm{keV}$ to $3 \mathrm{MeV}$ electrons. The electron beam is scanned so that the sample is homogeneously irradiated. The intensity of the beam is of the order of $0.1 \mu \mathrm{A} \mathrm{cm}{ }^{-2}$ in order to insure that the temperature of the samples never exceeds $50{ }^{\circ} \mathrm{C}$ during the irradiation. The sample is placed in a Faraday cup and the current integrated to account for possible fluctuations of the beam intensity.

Capacitive measurements are performed with the diode placed in a liquid nitrogen cryostat equipped with a temperature stabilization which allows linear variations of temperature with time (from $\sim 4 \mathrm{~K} \mathrm{~min}^{-1}$ up to $\sim 80 \mathrm{~K} \mathrm{min.}^{-1}$ ) from $80 \mathrm{~K}$ to $330 \mathrm{~K}$.

For transient capacitance measurements a standard Booton (model $72 \mathrm{~A}$ operating at $1 \mathrm{MHz}$ ) capacitance bridge is used. The biais pulses are applied through the bridge which introduces a time constant of $\sim 1 \mathrm{~ms}$. The transient signal is analysed with the use of two box-cars and the emission rates measured are corrected [15], when necessary, to account for the time constant of the capacitance meter.

3. Experimental results. - Prior to irradiation the analysis of the capacitance-voltage $C(V)$ characteristics reveals a constant profile of majority carrier, with a concentration $3.5 \times 10^{13} \mathrm{~cm}^{-3}$ at $77 \mathrm{~K}$.

As shown in figure 1, the TSCAP curves $C(T)$ exhibits after irradiation three stages, centered at about $100 \mathrm{~K}$ (stage 1), $135 \mathrm{~K}$ (stage 2) and $170 \mathrm{~K}$ (stage 3). The signal observed by transient spectroscopy is given in figure 2 before and after an annealing at $190{ }^{\circ} \mathrm{C}$ for $250 \mathrm{~min}$. The positions of the different levels observed have been measured. They are :

$$
\begin{gathered}
E_{\mathrm{I}}=0.18 \mathrm{eV}, \quad E_{\mathrm{II}}=0.23 \mathrm{eV}, \quad E_{\mathrm{III}}=0.32 \mathrm{eV}, \\
E_{\mathrm{IV}}=0.39 \mathrm{eV} \text { and } \bar{E}_{\mathrm{V}}=0.43 \mathrm{eV}
\end{gathered}
$$

from the conduction band.

Transient TSCAP measurements at various temperatures $T$, around the temperatures of the stages,

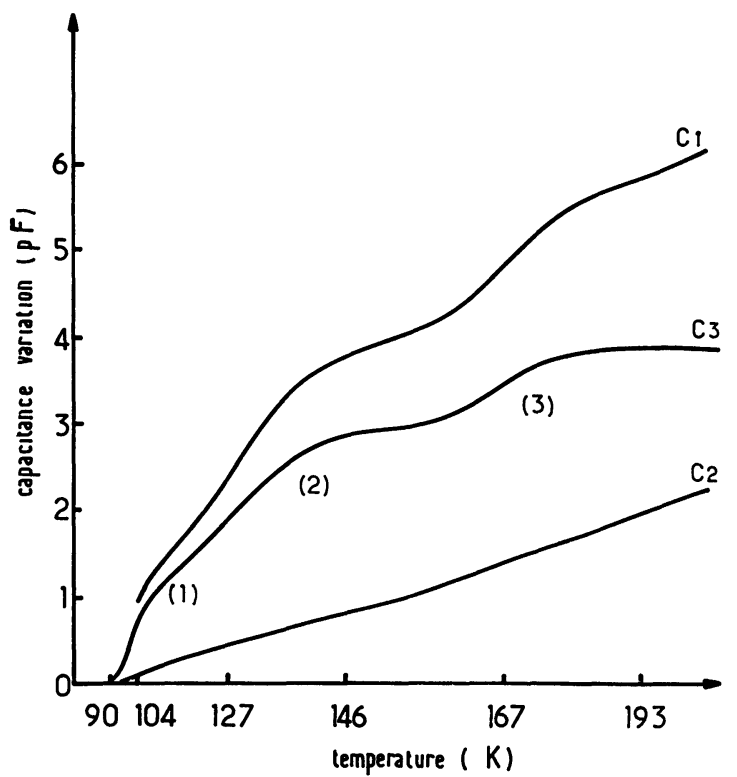

Fig. 1. - Typical TSCAP curve for an irradiated diode. $C_{1}$ is the capacitance corresponding to a $100 \mathrm{~V}$ reverse bias; $C_{2}$ is the capacitance at $0 \mathrm{~V}$ bias; $C_{3}$ is the difference between $C_{1}$ and $C_{2}$.

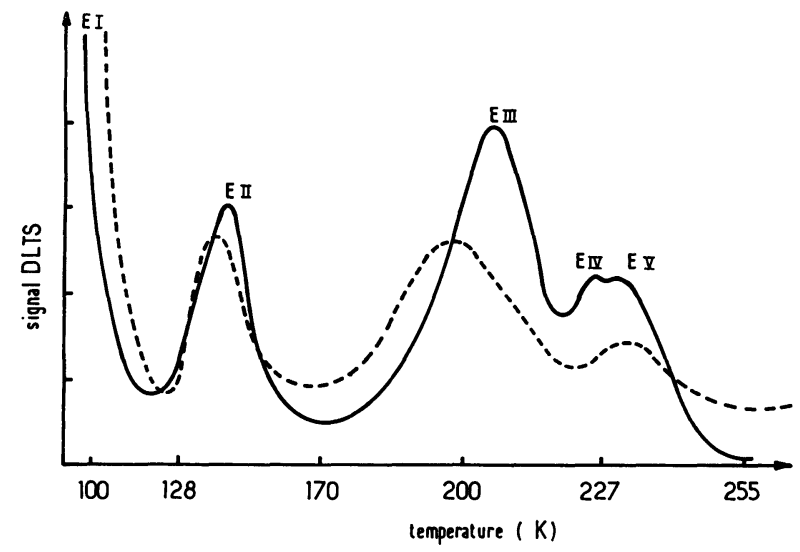

Fig. 2. - Typical DLTS curve for an irradiated diode before (solid line) and after (dashed line) annealing at $190^{\circ} \mathrm{C}$ for $150 \mathrm{~min}$ The rate windows are the following : $6.1 \mathrm{~ms}$ for the solid line and $9.0 \mathrm{~ms}$ for the dashed line. The rate windows being different the peaks appear at slightly different temperatures. The diode was irradiated with $5 \times 10^{14}$ electrons $\mathrm{cm}^{-2}$ at $1 \mathrm{MeV}$.

provide the emission rate $e_{\mathrm{n}}$ of electrons from the (acceptor) centers, from which the position of the associated level in the gap is deduced (from the plot of $\ln \left(e_{n} / T^{2}\right)$ versus $\left.T^{-1}\right)$. It is found that stages 1 and 2 correspond respectively to $E_{\mathrm{II}}$ and $E_{\mathrm{III}}$. Stage 3 is the sum of $E_{\mathrm{IV}}$ and $E_{\mathbf{V}}$; this can be seen when a $190^{\circ} \mathrm{C}$ annealing is performed, which induced the recovery of $E_{\mathbf{v}}$ (see Fig. 2).

The level $E_{\mathrm{I}}$ is not directly observed with TSCAP measurements : it occurs at a temperature lower than $80 \mathrm{~K}$ and only induces an increase with temperature of the base line of the TSCAP curve.

The cross-sections for electron trapping on these levels have been estimated from DLTS measurements through the extrapolation of the curve $\ln \left(\tau_{\max } T^{2}\right)$ 
Table I. - Energy levels and cross-sections for electron trapping for the different levels observed.

$\begin{array}{ccc}\text { Level } & \text { Energy }(\mathrm{eV}) & \begin{array}{c}\text { Cross-section } \\ \times 10^{-15}\left(\mathrm{~cm}^{-2}\right)\end{array} \\ - & - & - \\ E_{\mathrm{II}} & 0.23 & 3 \\ E_{\mathrm{III}} & 0.33 & 0.9 \\ E_{\mathrm{IV}} & 0.39 & 2 \\ E_{\mathrm{V}} & 0.43 & 7\end{array}$

versus $T^{-1}$ for $T=\infty\left(\tau_{\max }\right.$ is the rate window). They are given in table $\mathrm{I}$.

The variation of the defect introduction rate (number of defect per incident electron) has been measured for the defects corresponding to the three TSCAP stages. The results are given in figure 3.

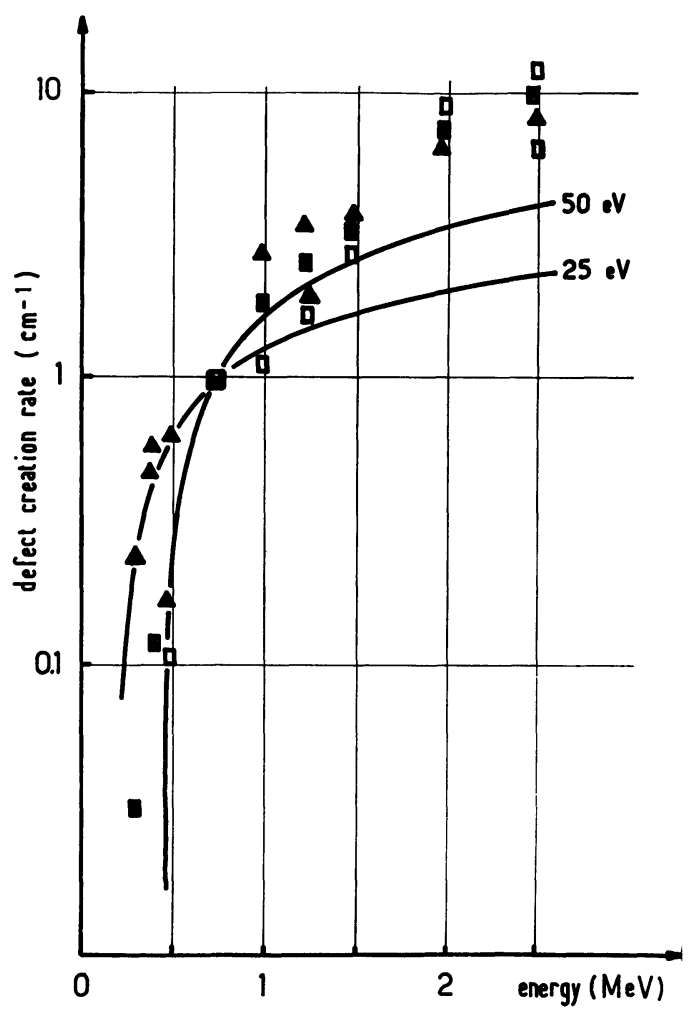

Fig. 3. - Defect introduction rates for the three stages versus the energy of irradiation $(\square$ stage $1 ; \square$ stage $2 ; \Delta$ stage 3 ). The full lines correspond to the theoretical variations for vacancy type defects $(25 \mathrm{eV})$ and divacancy type defects $(50 \mathrm{eV})$.

4. Discussion. - The defects introduced by electron irradiation in n-type silicon have been studied by Evwaraye [6-8, 10] and Kimerling [3] and the levels we observed have been also reported by these authors. Some of the levels were attributed to identified defects whose energy level positions were known : $E_{\mathrm{I}}$ to the vacancy-oxygen (A) center [5-12], $E_{\mathrm{II}}$ and $E_{\mathrm{IV}}$ to the divacancy $[5-9,11,12], E_{\mathrm{V}}$ to the phosphorusvacancy pair (E center) [13]. The $E_{\mathrm{III}}$ level, also observed by Evwaraye [9], has not yet been identified. The values of the cross-sections for electron trapping we evaluated are in reasonable agreement with the values reported in the literature. They are within a factor of two equal to the values published for $E_{\mathrm{III}}$ [9], $E_{\mathrm{IV}}$ [13] and $E_{\mathrm{V}}$ [7]; our value found for $E_{\mathrm{II}}$ is similar to the one published in reference [9] but a factor of 10 too high as compared to the values published in references [7] and [13].

As shown in figure 3, the defect creation rate (concentration of defect in the stage divided by the electron dose) $\tau_{3}$ of stage 3 seems to follow the theoretical curve [16] corresponding to a threshold energy of $25 \mathrm{eV}$ for low energies (lower than $1 \mathrm{MeV}$ ); this is consistent with the fact that it is associated with $V$-P pairs (the divacancy concentration is negligible for these energies, but not for higher energies). Also, in the low energy range, the defect creation rate $\tau_{1}$ of stage 1 seems to follow the theoretical curve for $50 \mathrm{eV}$; this is consistent with the fact that this stage is ascribed to the divacancy. The accuracy of the measurement of the defect introduction rate $\tau_{2}$ of stage 2 was even lower than for stages 3 and 1 and it cannot apparently be ascribed to any of the two theoretical curves. This low accuracy is due to the fact that it is difficult to compare quantitatively capacity changes between different diodes. In order to avoid this difficulty we plot in figure 4 the ratios $\tau_{2} / \tau_{1}$ and $\tau_{3} / \tau_{1}$,

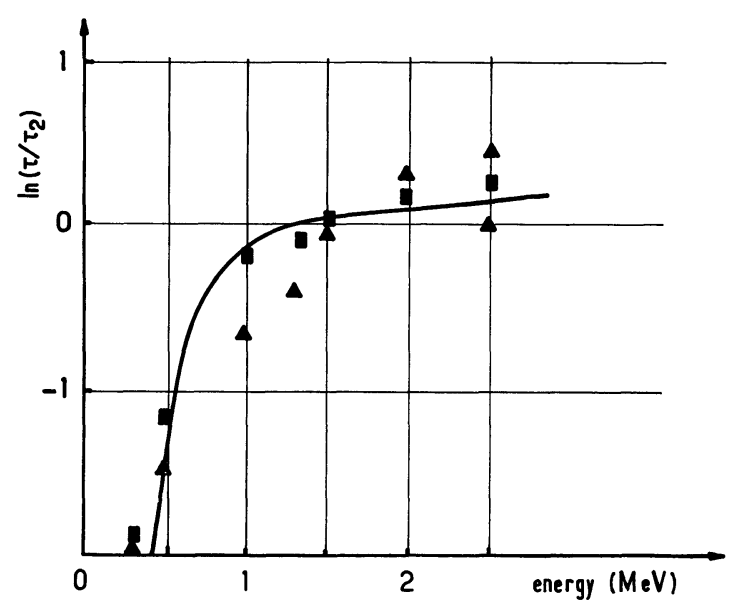

Fig. 4. - Variation of $\ln \tau_{3} / \tau_{2}(\boldsymbol{\Delta})$ and $\ln \left(\tau_{2} / \tau_{1}\right)$ (a) versus the energy of irradiation. The full line corresponds to the theoretical curve.

versus the energy of irradiation, for the same diode. We observe in this case that these ratios are clearly in agreement with the theoretical curve giving the ratio between vacancies and divacancies creation rates.

We can therefore conclude that stages 2 and 3 correspond to a threshold of $25 \mathrm{eV}$ and stage 1 to a threshold of $50 \mathrm{eV}$.

5. Conclusion. - The results we present here are in good agreement with the results reported by Evwaraye. The energy dependence of the defect creation 
rates for the three defects we studied provide a direct confirmation of the identification which was previously proposed : the $0.23 \mathrm{eV}$ is associated with the divacancy and the $0.43 \mathrm{eV}$ with the phosphorus-vacancy pair. In addition we demonstrate that the $0.32 \mathrm{eV}$ is associated with a vacancy-type defect.

\section{References}

[1] For a recent review on defects in electron irradiated silicon see for instance : Corbetr, J. W., Bourgorn, J. C., Cheng, L. J., Corelli, J. C., Lee, Y. H., Mooney, P. M. and WeIGEL, C., in Radiation Effects in Semiconductors, ed. N.B. Urli and J.W. Corbett (Institute of Physics, London) 1977, Conf. Ser. 31, p. 1.

[2] This technique was introduced by LANG, D. V., J. Appl. Phys. 45 (1974) 3023.

[3] A review on capacitance transient spectroscopy can be found in Miller, G. L., LANG, D. V. and Kimerling, L. C. Ann. Rev. Mater. Sci. (1977) 377.

[4] Brabant, J. C., Pugnet, M., Barbolla, J. and Brousseau, M., J. Appl. Phys. 47 (1976) 4809.

[5] Walker, J. W. and Shah, C. T., Phys. Rev. B 7 (1973) 4587.

[6] Evwaraye, A. O., J. Appl. Phys. 48 (1977) 734.

[7] Evwara Ye, A. O. and Sun, E., J. Appl. Phys. 47 (1976) 3776.
[8] Evwaraye, A. O., J. Appl. Phys. 48 (1977) 1840.

[9] Evwaraye, A. O., J. Appl. Phys. 47 (1976) 3176.

[10] Evwaraye, A. O., J. Appl. Phys. 29 (1976) 476.

[11] Sigfridsson, B. and Lindstrom, J. L., J. Appl. Phys. 47 (1976) 4611.

[12] Mooney, P. M., Cheng, L. J., SÜli, M., Gerson, J. D. and Coḱbett, J. W., Phys. Rev. B 15 (1977) 3836.

[13] Kimerling, L. C., in Radiation Effects in Semiconductors, ed. N. B. Urli and J. W. Corbett (The Institute of Physics, London) 1977 Conf. Ser. 31, p. 221.

[14] Watkins, G. D. and Corbett, J. W., Phys. Rev. 138 (1965) A 555 .

[15] Guldberg, J., J. Phys. E 10 (1977) 1016.

[16] Bourgoin, J. C., Ludeau, P. and Massarani, B., Revue Phys. Appl. 11 (1976) 2791. 